\title{
Frequent Emergency Calls for Crisis Consciousness-Building Effective Emergency Prevention System
}

\author{
Liu Yi ${ }^{1}$ Guo Yan ${ }^{2}$ \\ ${ }^{1,2}$ School of Humanities, Donghua University, Shanghai, P.R. China, 201620 \\ (E-mail:dhuly2005@163.com, 55564193@qq.com)
}

\begin{abstract}
In recent years, the content of emergency is expanding constantly in China. Both variety and frequency of emergency have been given a new meaning. Such as natural disasters, accidents, disasters, public food emergency, health events and sudden social security has occurred frequently. It brings that severe losses in the people's lives and property, economic development and social stability in some certain, it is a serious threat to public safety. How do deal with these emergencies in effective, timely, appropriate and peaceful? Not only is the focus of the party and the government and the whole society, but also it is a direct relationship to national economic, political and social stability. To deal with emergency, which requires us to continue to sum up the experience of dealing with emergencies at home and abroad to improve the sense of crisis and to establish the effective prevention of emergency management system, improved for dealing with emergencies ability at the first time.
\end{abstract}

Keywords: Emergency, "South snowstorm in early 2008" event, Crisis sense, Prevention system

\section{Introduction}

China has entered the risk society, which is predicted by a well-known German sociologist Ulrich Beck in the 1980s. However, currently China being transition of social, the several of risk and unexpected events occur frequently. It becomes the hotspot of global concern and focuses on. Emergency management has become an important issue in the global world. In China in 2003, SARS set off a "hurricane" of the incident, since then a variety of harm individuals, enterprises, social organizations and public safety, government, and even national emergency crisis a common occurrence: Wuxi algae in Tai Lake event in 2007, We chuan earthquake in may 12, 2008, the southern snow disaster in early 2008 , "6 28" Wonga mass incident in 2008, Chongqing taxi strike in 2008 , the Olympic torch overseas delivery attacks on the Sanlu milk powder incident, five miles flooding accident, "11 15 " major fire accidents in Shanghai in 2010 , rush to buy iodized salt incident in 2011, dyed bread incident in Shanghai, lean ham event, $\mathrm{He}$ Hailun The paper fraud case in Zhejiang University, the Zhou Jiugeng price cigarettes event, "My dad Gang" events, and so on. Emergencies like Hurricane left us damage and the loss is enormous, and the wounds can not heal. The data provided according to a global disaster statistics between 1996 and 2000, a variety of disaster crisis caused direct economic losses of up to $\$ 235$ billion, and 425,000 people were killed. 2Frequent emergencies, which urgent us increase our crisis sense. So that it seems imminent to build the effective prevention system in public crisis management.

\section{Deeply taping emergencies}

\subsection{Connotation of emergency}

From the international perspective, it called Emergency, Disaster, Hazards, Breaking news (Hongkong Phoenix TV news report series). 1In Western countries, have special emergency organization, such as the famous FEMA ( Federal Emergency Management Agency ) in the United States in 1979, HOEPD ( Home Office Emergency the Planning Division ) in UK, EMA ( Emergency Management Australia )in Australia, ADPC( Asian 
Disaster Preparedness Center ) in Thailand and other organizations.

China is not an independent and permanent coordination mechanism in emergency management. According to the disaster process, all levels of government office set up a temporary working group after the every disaster happened. Which temporary office is only in charge to respond emergencies. Although China has no unified organization responsible for the incident, It appears in each sector emergency response office management mechanism and the temporary working group. It is defined as all kinds of concept by academic research in China, has not yet formed a unified concept. In the legal level, the twenty-ninth meeting of the Standing Committee of the session of the Tenth National Congress has adopted "the people's Republic of China the emergency response law" on August 30, 2007. And it has implemented in November 1, 2007. it has give to certain concept, emergency, which is suddenly, cause or may cause serious harm to society, need to take emergency measures to respond to natural disasters, accidents, public health incidents and social security incidents. According to the degree of social harm, the extent of such factors, it divided as natural disasters, accidents, public health incidents. On the level, it has divided four levels: I, II, III, and IV. I is particularly great, II is great, III is more and IV is general level. However, all of levels must followed by the provisions of Laws, administrative regulations or State Council.

In short, the emergency has its own characteristics. First of all; it is sudden, unexpected events than common. Secondly, the whole event is a lot of uncertainty. Finally, the event will cause serious social harm or disaster. Although emergency is a sudden unexpected and uncertainty event, making prevention difficult. Chinese Confucian classic "Book of Rites - Doctrine of the Mean" Mean: "Forewarned is forearmed, without prejudging is will be canceled." In addition, Michael Regester, the British crisis management expert, who was saying: "Prevention is the best way to solve the crisis". Visible, it is the only way to reduce the social harm or disaster caused by emergencies is prevention.

\subsection{The analysis of cases reveals the importance of prevention}

2.2.1 Southern snowstorm disaster in early 2008 events caused disaster

"South snowstorm in early 2008 "event, from 10 January to 15 February 2008, lasted 30 a few days of snow and ice storms the State Council issued the" to the State Council approved on the coal, electricity and rescue and disaster Emergency Command Center a notification on the work of rescue and disaster and post-disaster reconstruction report ". SAN, February 14, preliminary statistics from the Ministry of Information Industry said snowstorm caused direct economic losses reached 1.1 billion RMB in industry, relief inputs accumulated about580 million. 3 Hong Kong's Wenhui Po reported, the reporter learned from the Ministry of Civil Affairs, the South recent snow disaster has caused direct economic losses of 151.65 billion RMB. At current exchange rates, the economic losses caused by the snowstorms on China has more than five years ago of SARS, 127.86 billion RMB. 4 February 24, 2008, Xinhua quoted Vice Minister of Civil Affairs Li Liguo said snow and ice storms occurred in the South recently has resulted in 129 people dead, four missing, 166 million evacuated. 4 85,000 houses collapsed and tolls direct economic loss of 151.65 billion RMB.5

2.2.2 The analysis of Southern snowstorm disaster in early 2008 events process

The whole things On South snowstorm in early 2008, a description of the process and reports is similar. summarized, scholar Wang Jing think of the event experience for our government and public understanding of the whole incident has descript as: the process from "snow", "snow more than", " snowstorm "to" Snow disasters ".6In addition, some other scholars will this event is divided into: "celebrate the Snow in Southland, the Government has ignored the crisis", "Snow and eventually became a snowstorm, the crisis on the agenda", "Government mobilize people fight to the disaster, the preliminary settlement of the crisis. 7

Seen the whole incident in the prevention of system has a lot of problems, almost a week, the south was heavy snow in a wide range. It is unusual. At the beginning, the government and its industry and other related departments failed to attach. Because of the lack of sense of 
crisis in these sectors, there is no effective in early warning of potential crisis. The result is the public no time to adjust travel plans, to prevent the freezing weather, which delayed the best time of crisis response. The snow is still wanton blowing, next week's time, China has caught up with the Spring Festival return of passenger flow peak of our country there is no specific emergency response organizations. When emerging incidents, the State Council Emergency Management Office in January 21, issued circular, central ministries to activate contingency plans. While the slow response of local governments, combined with the central and local upload issued a poor, poor communication between the lateral institutions lead to crises-prone.

2.2.3 Southern snowstorm incident in early 2008 has revealed the importance of effective prevention

The Great Southern Snowstorm in China defeat at the "pre" in 2008. 7From government to local of relevant department they all lack on crisis sensitivity. They lack of a sense of crisis and poor ability to identify crisis. And crisis prevention and management mechanism is poor. There is no effective prevention system. When the crisis has occurred that the response to potential crisis will lead to huge disaster. In early 2011, in southern provinces of China, which are Guizhou, Hunan and Hubei Guangxi. Ice storm affecting hundreds of thousands of people travel disruption grid overlying ice, some areas were without power without water. 383.3 million people were affected, an area of 142.4 thousand hectares of crops were affected. 8Due to the experience in 2008 , at the outset, causing the attention of various government departments, the incident did not rise to the crisis agenda. The importance of prevention is visible.

\section{Experience of domestic and international emergencies prevention}

\subsection{From the legal point of view}

He legal means are emergency prevention and effective way. In response to unexpected events lead to great disaster, additional national legislation is important. "Communicable Disease Prevention Law "was promulgated in 1989 in China. From the 2003 SARS outbreak, the State Council promulgated "the Emergency Ordinance for public health emergencies". On
August 30, 2007 the Tenth National People's Congress Standing Committee on the ninth meeting of the People's Republic of China adopted by law on emergency response and enters into force on November 1, 2007. Up to now, the legal system of crisis management in China has basically taken shape. There are 35 public emergency response to the legal, 37 administrative rules and regulations, 55departmental rules and regulations and 111 of the relevant laws and regulations. 9in the United Stated in 1950, the first to respond to emergencies laws "disaster relief and economic aid," the latter more than the legal issue "Earthquake Disaster Mitigation Act," National Emergency Law, "against international terrorism Act", "the Public Health Service The introduction of the Act", "to guard against mass destruction weapons 1996 Act" etc. After "9 • 11 incident", Homeland Security Act" in November 25, 2002"and other laws has risen. Russia issued in 1999, "Commonwealth citizen health epidemics and epidemic prevention law". Japan as a natural disaster frequency-prone countries to issue "health of the law" in 1947 and "disaster Countermeasures Basic Law" in 1961. In June 6, 2003, Japan's House passed a so-called "emergency three bills", is, "response to Armed Attack Situations Act"," the Security Council of Law for Amendment" and" the SDF Law Amendment". South Korea has more than 40 laws relating to communicable diseases.

\subsection{From the government perspective}

According to statistics, the U.S. Federal Emergency Management Agency (FEMA) was established in 1979 and gradually formed a complete set of incident management system. Public administration institutions sometimes set up a temporary institution to deal with emergencies in the UK. Protection emergency prevention office is a permanent federal emergency response to the specialized agencies in Canada. Different levels of regulatory agencies in Australia: the central set of anti-crisis task group (CCDTF), the Federal Emergency Management Agency (EMA), leadership and coordination of the National Disaster Work Country Crisis Management Center (NEM-CC). Agency for Public Management epidemiological investigation team was established in 2000 as a rapid reaction force in Korea. There is no uniform emergency response agency in China. Combined with China's specific national 
conditions, "the emergency response provisions of the Act" pointed that: State to establish a unified leadership, coordination, classified management, graded responsibility, territorial management based emergency management system. 10

\subsection{From view of science and technology and information technology}

With the development of network and IT, It has combined early warning management of public crisis with China's rapidly developing e-government construction. And warning the public crisis management has as part of the e-government. There are integrated applications of Internet technology, cluster the wireless network the GJS technology, satellite communications technology, GSM wireless communication and fast gateway data exchange technology. At the same time, fully integrated multi-sectoral, multi-industry, multi-level systems and the information resources, it can help to achieve real-time response and dispatching of public crisis, and provide the public with the appropriate emergency services. 11

Italy's national emergency committee is responsible for major emergencies and rescue decision-making consultations. And information technology and communications technology are widely used in the emergency management of emergencies. Has established a decision-making chain of command, responding to public emergencies emergency rescue information sharing system, the resource allocation system and the joint office mechanism, and network and communications technology, disaster monitoring system from the agencies' real-time access to a variety of public emergencies message. At the same time, the application of advanced disaster assessment data model, the establishment of disaster assessment system to provide a scientific basis for judging disaster trends, predictions and rescue decision-making.

It was launched two intelligence-gathering satellites in Japan in 2002 and 2003. Japanese Prime Minister's official residence within the emergency management center is the most important facilities in Japan incident management. the facility with the related ministries and agencies to connect hotline (telephone, fax), satellite cellular phones, emergency PBX and other communications equipment, large LCD projection equipment, etc.. It is also equipped with a difficult to interfere with, the most advanced information communications equipment, with the Internet map data terminal, weather information terminals, communications, data terminal, terminal equipment, the video conference, transfer images, maps and other data. 12

\section{Establishing Effective Emergency Prevention System}

In 2004, the Party's fourth plenary of sixteen session definitely required: to establish a sound social early warning system, form a unified command, the all functioned, sensitively response, efficient emergency mechanism. Ensure public security and improve the ability of emergency manage ability 13. When in emergency must adhere to prevention, must "peace with sword in hand, thought is be prepared, and prepare"as "Zuo Commentary" said, put the center of the work in advance of prevention, then when in a crisis period, we can do it in an orderly way. Famous American entrepreneur Osborne and Gabler pointed out the aim of crisis management is "Use a small amount of money prevention, and not spend a lot of money for treatment." 14Frequently emergency makes the effective way to prevent more important. With the development of science and technology and related areas of research results increasing, a global of continuous improvement to unforeseen events the attention, construct effectively incident prevention system has become a feasible and important agenda.

\subsection{From Public View: the Scientific Culture of Prevention}

Three characteristics of the incident: suddenness, severity and can not be expected to nature can easily lead to psychological fear of the public, and even lead to the irrational behavior of the public, resulting in further losses of unexpected events. Therefore, the strength of the public sense of crisis is directly related to the effect of the Government's crisis management.

\subsubsection{Public Weak Sense of Crisis}

In daily life, walking without see is likely to be tripped and eating without pay attention may also be choked. The sense of crisis, as the saying goes: no one thought there must be close at hand. We have to always wish to 
careful risk is no one can guarantee that the next second is very safe. Actually for quite a long time, when the public hear the sense of crisis, perhaps they would feel that is the matters of government departments and business units, rather than ordinary things of the people. However, when the "Wenchuan Earthquake", "2008 Southern snowstorm event"," Sanlu milk powder incident" relates to the daily life, people suddenly realized the importance of crisis prevention awareness.

4.1.2 Improve Crisis Prevention Awareness of the Public

China is one of the few countries which suffer the most serious losses from natural disasters in the world, besides China is the world's most populous developing countries. Whether in academic theory or in practice the process of emergency response is still lacking. The biggest crisis for Chinese people is the lack of awareness of crisis, particularly the lack of awareness of disaster crisis. According to statistics, about 200 million people of the national population are affected by disasters each year, the direct economic losses is more than 100 billion RMB. There are so many emergencies like Car accident, boat crash, train crash, plane crash, subway bombings and other kinds of traffic accidents, snow disaster, food poison, major epidemic, earthquake, fire, riot, leakage, typhoon, flood, drowning, lightning, chemical spills and terrorist crises. Natural disasters and hazards public safety emergencies frequently happened in China due to the weak sense of crisis.

Firstly, in the ideology level, people must change from the "incident handling" to "prevention" in advance. For example, a large number of American films and television literatures are related to the crisis awareness, using multiple methods, including the warning call, warning, prophecy, etc. It is said that whenever the Japanese tourists came to the hotel, after they lay down their luggage, first thing is to look at the fire exits. When can our Chinese people do this? Strong crisis awareness of American and Japanese is worth to learn. So let people concerned about all kinds of warning signs and the correct response to accident in their daily lives. Do not panic in the real incident and with the correct method to escape in a short period of time or do disaster prevention.

Secondly, in the culture and education of level: with the arrival of the crisis breaking out frequently, it is the high time to carry out a systematic crisis education. From "the Wenchuan earthquake", China began to focus on disaster prevention education in schools. But primary and secondary schools of our country who carry out the "crisis of education", "disaster education" essential "frustration education is still far from entering a normal track, so far there is no decent, prepared textbooks written by the real experts and teachers of disaster prevention and mitigation Currently the new national curriculum system still has no specialized courses to respond to natural disasters. We can learn from the Australian disaster prevention and education, to establish the National Emergency Management Institute to develop crisis management professionals.

Thirdly, the propaganda of the government and society level: hand out promotional materials can help people learn about crisis events in a short time. And take scientific actions to handle the accident. Increase special issue columns in newspapers and magazines, radio and television film and Internet propaganda. vigorously carry out publicity and education of emergency alerts, such as reported the typical case, exhibit preventing alerts education pictures and videos road show. Every year on this day, may 12, all over the country will organize large-scale disaster prevention exercises. One of the exercises is how to how to organize or participate in disaster relief during an earthquake.

\subsection{The Government's vision: sound the emergency prevention system}

\subsubsection{Sound laws and legal system}

4.2.1.1 The importance of a sound legal system Especially in our current law is not fully developed, there are a variety of defects in the process of the country's legislative, judicial, law enforcement, and people's awareness of the law is not strong, so often lead to sudden acts of violent resistance to law and other events, such as: 2008 "6.28" Weng'an mass incident and "Green Sea incident" on October 23, 2008. The formulation of the law is extra important.

To establish unified and comprehensive coordination of a combination of the legal system

To respond to emergencies, the government's administrative power is an 
irresistible trend of expansion, in order to strictly regulate the powers exercised by the Government in exceptional circumstances. Establish a standardized system of laws and regulations is imperative. In addition, they are an important guarantee for the prevention, and emergency measures adopted laws. Organizational command structure through the development of laws and regulations to establish a unified, clear the responsibility of all departments and agencies on the precaution and the emergency measures in public emergencies and straight out the integrated management system. Through pass legislation to determine the community and the citizens in emergencies position, responsibilities, obligations and rights, in order to ensure stable and orderly social system in an emergency. In response to the SARS epidemic, China's rapid and successful development of "the Emergency Ordinance for public health emergencies", play to regulate and protect the role of prevention and control of public health emergencies. But, enacted various laws and regulations in China have a strong authority, independence, and the main management of the department seriously so that the different functions between the agencies in the implementation process collaboration is difficult to handle the event.

Therefore, the urgent need of integrated, comprehensive and systemic laws adapt the needs of the times as the guiding ideology to respond to emergencies and the program of action. To develop uniform laws and detailed regulations, making the regularly relationship between the normative government and citizens in the period of the occurrence of unexpected events, to protect the Government to exercise fully and effectively emergency administrative rights in emergencies, to limit effectively its power under the specification legal, to protect citizens' basic constitutional rights is not be infringed when the occurrence of a state of emergency has. At the same time, a permanent unified national incident management coordination department should be established, in order to deepen and regulate the linkage mechanism for social services, and national legislation and relevant laws and regulations clearly require institutional coordination of departmental emergency center, functional status, power the duties and obligations of the operational flow, etc.

Reasonable contingency plans for development
The so-called contingency plans is expressly provided in Article 18 of the "Emergency Response Act": emergency plan should be in accordance with the provisions of local Law and other relevant laws and regulations for the emergency nature, characteristics and may cause harm to society, including the specific the provisions of the emergency management organization and command system and the duties and emergencies prevention and early warning mechanisms, disposal procedures, emergency safeguard measures and the subsequent recovery and reconstruction measures, etc. Emergency response plan is a program of action to respond to emergencies, a guide to action, action-oriented. It is reported that: If a serious incident occurs, the efficiency of all levels of government have contingency plans and immediately start to take response measures, 320 times than opposed to no plans or unsound plan system awaiting presidential orders to take response measures 16.The formulation of reasonable contingency plans can not only reduce the tension and fear of the public, reducing lead the decision-making pressure to respond to emergencies, the rational allocation of the resource allocation of emergencies.

Reasonable contingency plans for the formulation of laws, regulations, rules and regulations must be combined to a specific role. The provisions of Article 17 of China's "Emergency Response Act": The State establishes a sound emergency response plan system. The State Council has formulated emergency response plans for national emergencies, and organizations to develop specialized emergency response plan for national emergencies. Relevant departments under the State Council according to their respective responsibilities and the State emergency plan formulated contingency plans about department of national emergency. The actual situation of local people's governments and above the county level people's governments at the relevant departments according to relevant laws, regulations, rules and regulations, the higher level people's governments and relevant departments of the contingency plans, and the actual situation of the region, develop appropriate contingency plans for emergencies. The emergency plan-making organs should be based on actual needs and situation changes, the revised contingency plans in a timely manner. The 
State Council formulated the contingency plans and the revised procedures. Have standard and reasonable contingency plans, we will face the unexpected events can chicken without the mess footing enhanced to prevent and respond to scientific rationality.

\subsubsection{Building a Strong Government} Institutional System

The emergency response agencies system of our government is constantly improving during last decade. Our response to public emergencies during the SARS epidemic has mainly taken the form of establishing a "temporary headquarters". In December 2005, the State Council set up the Emergency Management Office of the State Council (State Duty Room). And up to the end of 2006, 30 provinces (autonomous regions, municipalities) has set up or definite the office of emergency management leadership, while 96 percent of the municipal government, and 81 percent of the county government has established or definite the office. 4For example, in the case of Zhejiang Province, the total number of all kinds of its provincial management agencies of public emergency is 48 as the end of 2006, which has 7 approved establishment of official documents, and 41 clearly established in the relevant plan, involving four types of public emergency management. Zhejiang Province has made the initial formation of the public emergencies organization system centered by provincial government for emergency command center, and supported by 48 special public emergency management agencies. Below the provincial level, Zhejiang has 11 municipal government established government emergency management office, 10 cities of which are for full-time emergency management offices, and one city of non-full-time emergency management offices. Meanwhile, 90 governments of counties (cities, districts) has established emergency management offices, including 59 counties (cities, districts) for the full-time emergency management offices, and 31 counties (cities, districts) for non-full-time emergency management offices17. From above, we can see the gradual improvement of the system of our government agencies.

State Council is the highest administrative lead agency for government emergency management work In China. It involved by the starting point from the horizontal direction, related to the cooperation of the various regulatory agencies and departments. From the vertical direction, it set the close collaboration between the lower levels.

\subsection{From the Technology Perspective: Establishing Effective Emergency Prevention System}

\subsubsection{Effective Dealing with Information}

So-called information processing is through specialized staff thinking, judgment, and reasoning. using modern scientific methods and first-hand material, a thorough understanding and investigation of unexpected events. Analyze the causes of events and the status quo, the extent of losses, pre-development trends social impact, the formation of a detailed investigation report and provide a reliable basis for dealing with emergencies, and develop appropriate countermeasures.

Ensure the quality and quantity of information by the collection of information.

In the information age, the use of high technology and its tools has made substantial contributions to the collection of information. First, it is information dissemination and disclosure of the legal system. It is the government's social responsibility to provide true and reliable to the society. Collecting specification information from the legal point of view makes the collection of information operability of modern technology more reasonable. Second, there are information systems and the diversification of collection process.

Only far from the information gathering process, can it to make the raw data which has not yet been processed to present a more realistic and complete the form, and through its diverse benign complementary organizations to make the right response 18 .

Collation of information

The collation of information is to classify data summary information which has been original monitored and scanned, with the help of high-tech technology, following the "wheat from the chaff and discriminating" guidelines, screening, and analyzing the expansion and filter refining process. First is the specialization of information processing and recognition. In the era of diverse information, we should identify information, and take use of the information. Then you have to give full play to the role of the expert or professional organization. Besides, effective access to 
valuable information is also required. Second is the assessment of information processing. Basis to confirm the authenticity of the information in emergencies, the different information categories stored, so that information in a systematic and well-organized in order to expand the assessment. The assessment focus is to capture the sign of the signal, early prevention efforts so that the weak link will not be forwarded to the crisis, and may be caused by the crisis assessment.

4.3.2 Increasing Research Investment and Establishing an Effective Prevention System

Establish a high-tech information on prevention, the key depends on whether the technology is advanced, it is critical to the efficiency of the system. Effective system should be a set of voice, data, images as a whole, the basis of the information network, and the various sub-systems to the organic interaction as a whole. Especially forecasting system for natural disasters, with the development of networking and information technology, natural disaster mitigation and prevention has important significance of the system involves many interdisciplinary. First are communications systems, advanced digital trunked radio communications systems, electronic systems, wireless communication systems. Second is police assistance system. Computer assisted system (CTI technology to achieve pre-connected, linked reporting system with electronic map systems) unified answer and deal with the police, help information automatically and quickly display the alarm the full address of the person, the nearby police and rescue resources distribution 19. Third are chain of command, command platform of multimedia human-computer interaction, and leadership decision-making chain of command and decision support systems. The system includes GPS subsystem and CIS subsystem, statistical analysis systems, and security systems 20 .After continually using advanced technology to improve the system, allowing the system to continue to inject new elements. we can guarantee the effectiveness of the system. 8

\section{Conclusion}

Prevention of emergencies effectively avoids the occurrence of unexpected events or emergencies to minimize the disaster. There are various preventive and preparation in our thinking and action, organization and management, the finest aspect of the legal provisions. Former Secretary General Kofi Annan said: "First of all, the cultural aspects from the concept of the reaction is converted to the idea of prevention from the long-term interests, the most important and primary task is to reduce the number of disaster and loss prevention is not only more than the relief humane, cost more. "21Incident prevention is more important than handling the incident. To build the emergency prevention system, to some extent, before unexpected events did not occur in a timely manner their root causes to eliminate, so that you can solve a lot of manpower, material and financial resources.

\section{References}

[1] Wang Jianxiong, crisis management, and sudden public events [J], Chengdu Institute of Public Administration, 2006 (2) (In Chinese)

[2] He Wenfa, emergencies and external reported [M], Communication University of China Press, 2008 265-267 (In Chinese)

[3] http://www.sina.com.cn

[4] http://news.qq.com

[5] http://whb.cn

[6] Wang Jingbo, the typical analysis of public crisis management case - Emergency Management [M], Research Press, 2009: 128-130(In Chinese)

[7] Wang Fang, a classic case of crisis communication dialysis [M], China Social Sciences Press, 2010:165-167 (In Chinese)

[8] Wang Fang, a classic case of crisis communication dialysis [M], China Social Sciences Press, 2010: 89-91 (In Chinese)

[9] http://www.jstv.com/s/dongyuxiji/

[10] Gao Xiaoping, the emergency management system of Chinese characteristics, achievements and the development of $[\mathrm{M}]$, Chinese Public Administration, 2008 (11):235-236 (In Chinese)

[11] Lu Tao, crisis management [M], Publishing House, 2008(2) :2-5 (In Chinese)

[12] Zhong Zhaohua, "principal-agent perspective, public crisis early warning of the local government failure," master's thesis of the Hunan University, 2010 (4): 112-116 (In Chinese) 
[13] Qin Qiwen, emergency prevention and response to $[\mathrm{M}]$, Xinhua Publishing House, 2008(4) :98-100 (In Chinese)

[14] Kan sudden event report [M], China Times and Economic Publishing House, 2009 (1):26-28 (In Chinese)

[15] [America] David Osborne, Zhou Duiren ,reform of government - the spirit of enterprise is how to reform the public sector $[\mathrm{M}], \quad$ Shanghai Translation Publishing House, 1996 :135-136

[16] Liu Yong hair, the need for contingency plans developed by [J], China, for Disaster Reduction, 2005 (5) (In Chinese)

[17]Lang Peijuan Wangzhuan Hong, China 's government to public emergencies bodies [J], administration, 2007 (11) (In Chinese)

[18] W.Timothy Coobms. Ongoing Crisis Communication-Planning, Managing and Responding. London: SAGE Publications, Ins, 1999:

[19] Si yapping, The Addis level of public crisis management system $[\mathrm{M}]$, the Intellectual Property Publishing House, 2007 (11):68-69 (In Chinese)

[20] M. Martinsons. The balance Scorecard: a foundation for the strategic management of information systems[J],Decision Support Systems, 1999 (1)

[21] IDNDR, Early Warning Programmer Action Plan for the future (1998-1999), General, International Decade for Natural Disaster Reduction Secretaria,1999. 